\title{
Influence Of Geographical Area And Living Setting On Weight Status, Gross Motor Coordination And Physical Activity Level Of Italian School Children: The Neighbourhood Walkability Approach
}

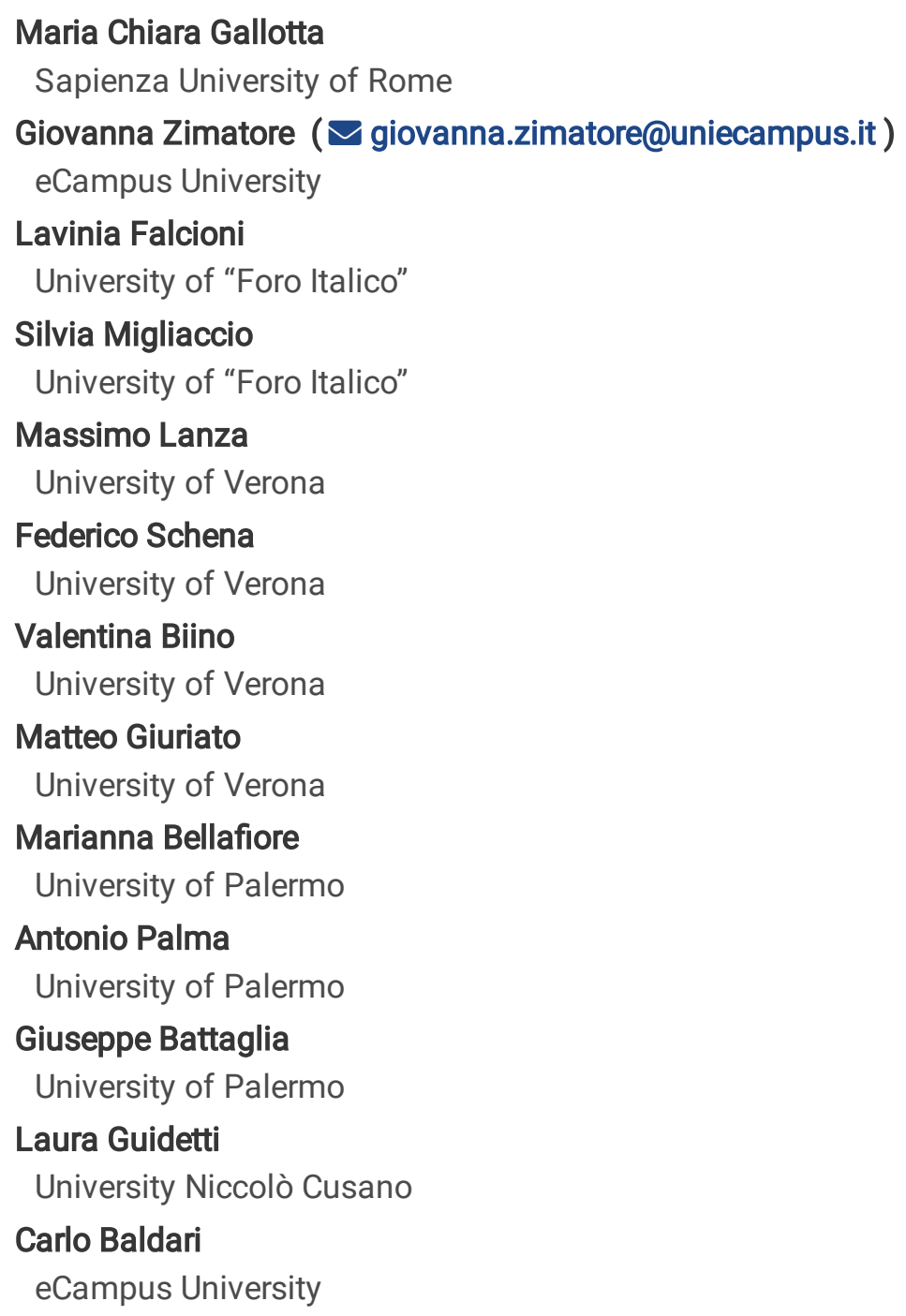

Research Article

Keywords: overweight, obesity, movement skills, gender, geographical area, living setting

Posted Date: April 27th, 2021

DOI: https://doi.org/10.21203/rs.3.rs-442564/v1

License: (c) (i) This work is licensed under a Creative Commons Attribution 4.0 International License. Read Full License 


\section{Abstract}

Background: The prevalence of overweight and obesity in childhood is increasing at an alarming rate worldwide, particularly in industrialized countries. Walkability measurements can be collected using the free open software Walk Score ${ }^{\circledR}$ that permit the measure of estimating neighbourhood walkability in many geographic locations. This study was aimed i) to investigate whether differences between rural and urban settings in the North, Centre and South of Italy could influence body-weight status, motor competence and physical activity (PA) level in school-age children; ii) to analyse the walkability of different school areas, and iii) to examine the relationship of motor competence, PA level, geographical areas, living setting, and neighbourhood walkability with children's body-weight status.

Methods: We assessed anthropometric parameters, gross motor coordination and PA level in 1549 children aged between 8 and 13 year. Three geographical areas (North, Centre, South of Italy), two settings (urban and rural) and neighbourhoods' walkability (Walk Score ${ }^{\circledR}$ ) were considered in the analysis.

Results: The prevalence of overweight and obesity was $22.0 \%$ and $9.9 \%$, respectively; $47.9 \%$ of the total sample showed motor impairments and $29.0 \%$ was inactive. Central children had higher BMI than Northern and Southern children. Northern children showed the highest MQ and PA level, followed by Southern and Central children. Children from the South of Italy attended schools located in neighbourhoods with the highest Walk Score ${ }^{\circledR}$. Urban children attended schools located in neighbourhoods with a higher Walk Score ${ }^{\circledR}$ than rural children. Lower MQ, lower PA level, living in rural setting and in a cardependent neighbourhood were associated with a higher relative risk for obesity. Being a girl was associated with a lower relative risk for obesity.

Conclusions: The alarming high percentage of overweight and obesity in children as well as motor coordination impairments revealed the urgent need of targeted PA interventions in paediatric population.

\section{Introduction}

The prevalence of overweight and obesity in childhood is increasing at an alarming rate worldwide, particularly in industrialized countries. The excess of body weight is strongly correlated with sedentary lifestyles, and therefore is related to low levels of motor competence [1, 2]. Studies reported a substantial decline in children's motor competence over the last 4 decades due to the decline of physical activity (PA) and the increase of sedentary behaviours [3]. Interestingly, recent studies conducted on Italian populations report that more than $30 \%$ of Italian children are affected by overweight or obesity [4, 5], $18 \%$ are sedentary, while $41 \%$ perform more than two hours of screen activities a day [4]. Sallis et al identified several environmental and demographic variables affecting children's PA level and obesity [6]. Urban and rural settings appear important conditioning factors for participation in PA and for development of fitness and coordination [7]. Studies have been conducted to identify the association between children and adolescents PA and the setting in which they live [6, 8]. The ease of access to safe and outdoor sites promotes PA in children who therefore improve their physical fitness and coordinative abilities [1, 9]. Contrarily, the lack of sidewalks and recreational facilities, the absence of ease of access to schools, the need to cross busy streets, traffic congestion and air pollution discourage children from playing outside or from walking and biking to school $[6,9,10]$, favouring an obesogenic environment [11]. Therefore, PA, obesity levels, and the associated motor competence during childhood, might correlate with the level of urbanization. Recent studies investigated the influence of living setting on anthropometric parameters, PA level, and motor competence in children, with inconsistent and contrasting results $[12,13]$. No consensus exists concerning a definition of residential areas in terms of urban and rural specificity since most studies define urban and rural setting only on population density [13]. Furthermore, obesity in childhood could be influenced by the spatial structure of street networks and by the aspects of the built environment [14], that modify neighbourhood walkability and, thus, PA levels [15]. The Italian peninsula, mostly within the Apennine mountain range, stretches for about $1.200 \mathrm{~km}$, in NW-SE striking sets leading to many different historical and geographical characteristics which determine significative socio-economic and lifestyle differences among northern, central and southern regions [4] and, also, between urban and rural setting [16].

Page 2/16 
Considering the scientific evidence reported, we hypothesized that geographical area and living setting could influence weight status, motor coordination and PA level of children. Therefore, the first aim of the present study was to investigate whether differences between rural and urban settings in the North, Centre and South of Italy could influence weight status, motor competence and PA level in school-age children. The second aim was to analyse the walkability of the different school areas. Finally, the third aim was to examine the relationship of motor competence, PA level, geographical areas, living setting and neighbourhood walkability with body weight status of Italian children.

\section{Materials And Methods}

\section{Participants}

One thousand five hundred forty-nine school children aged between 8 and 13 years volunteered to participate in this study. The population included subjects from 38 different Italian elementary and middle schools. The classroom demographics broke down to 391 Grade 3 children (8-9 years of age), 362 Grade 4 children (9-10 years of age), 351 Grade 5 children (1011 years of age), 234 Grade 6 children (11-12 years of age) and 211 Grade 7 children (12-13 years of age). The participating schools were enrolled to be broadly representative of Northern, Central and Southern schools, including the capital city (Rome) and the urban and rural areas, and to have appropriate and similar sports facilities to conduct comparable measurements.

The Institutional Review Boards of the University of Rome "Foro Italico", of the University of Verona and of the University of Palermo approved this investigation in accordance with the ethical standards laid down in the 1964 Declaration of Helsinki and its later amendments. Additional authorization was provided by school principals/administrators. Written informed consent forms were obtained from both parents and children prior to study participation.

\section{Anthropometric measurements}

Anthropometric measurements were performed to assess children's weight, height, and body mass index (BMI). Weight and height were measured using a scale and a stadiometer to the nearest $0.5 \mathrm{~kg}$ and $0.1 \mathrm{~cm}$, respectively. BMI was calculated as weight in kg divided by the square of height in meters. Children were classified as underweight (UW), normal weight (NW), overweight (OW), and obese (OB) using age- and gender-specific cut-off points [17].

\section{Gross motor coordination measurement}

Gross motor coordination was assessed by the Körperkoordinations Test für Kinder (Body Coordination Test for Children, referred to as KTK) battery [18]. The motor quotient (MQ), a global indicator of gross motor coordination adjusted for age and gender, was calculated on the raw values of the four subtests included in the battery (balance, jumping laterally, hopping on one leg over an obstacle, shifting platforms). The test-retest reliability coefficient for the raw score on the total test battery was 0.97 , while corresponding coefficients for individual tests ranged from 0.80 to 0.96 . Both factor analysis and intercorrelations indicated acceptable construct validity.

In the present study, children were categorized as "children with MQ impairments" (MQ score $\leq 85)$ or "children with no MQ impairments" (MQ score $\geq 86$ ) [18].

\section{Physical activity level measurements}

The Italian version of Physical Activity Questionnaire for Older Children (PAQ-C-It) was adopted to measure children PA level [19]. This instrument is a valid and reliable self-report measure, 7-day recall instrument designed to measure general levels of PA in school-aged children from ages 8-14. PAQ-C provided a summary PA score derived by 9 PA questions about the activities that a child might have done in the last 7 days. Each question was scored on a 1-5-points scale and the average was used to represent the activity level of the child [19].

In the present study, children were categorized as "inactive" (PA score $\leq 2$ ) or "active" (PA score $>2$ ), according to specific cutoff points [20]. 


\section{Geographical area and living setting}

Three different geographical areas were considered: North, Centre and South of Italy. Moreover, two different settings were considered: urban and rural setting, defined by population density (www.reterurale.it). According to this classification, urban areas have a population density higher than 150 inhabitants $/ \mathrm{km}^{2}$ and rural areas have a population density lower than 150 inhabitants $/ \mathrm{km}^{2}$. Population density was determined according to the most recent data provided by ISTAT (Istituto Nazionale di Statistica) Census (www.istat.it).

Seven hundred and seventy-two children came from the North of Italy (535 urban and 237 rural children), 411 children came from the Centre of Italy (181 urban and 230 rural children) and 366 children came from the South of Italy (268 urban and 98 rural children).

Northern-urban children comprised pupils attending 14 different schools located in Bolzano, Verona, and in the province of Treviso (Castello di Godego), Verona (Lugagnano, San Bonifacio, Bovolone, Castelnuovo del Garda, and Mozzecane), Mantova (San Giorgio Bigarello) and Padova (Casale di Scodosia), while northern-rural children included pupils attending 7 different schools located in the province of Verona (Roverchiara, Casaleone, Minerbe, and Poiano) and Padova (Castelbaldo, Masi, and Merlara). Central-urban children comprised pupils attending 6 different schools located in Rome, while central-rural children included pupils attending 4 different schools located in the province of Rome (Montelibretti, Montorio Romano, Monteflavio, and Nerola).

Southern-urban children included pupils attending 6 different schools located in Palermo and in the province of Palermo (Villabate), while sourthern-rural children included pupils attending 1 school in the province of Messina (Mistretta).

\section{Neighbourhood walkability}

Walkability measurements were collected using the free open software Walk Score ${ }^{\circledR}$ (WS; www.walkscore.com). Walk Score ${ }^{\circledR}$ is a valid measure of estimating neighbourhood walkability in many geographic locations [21]. Each children's school address was manually entered into the Walk Score ${ }^{\circledR}$ and from here the walkability of the different school areas was analysed. For each address, the Walk Score ${ }^{\circledR}$ calculates all the different walking routes to nearby amenities (public transit stations, grocery stores, retail stores, parks, schools) producing, through an algorithm, a score ranging from 0 to 100 . A scores of 100 is assigned to districts that have amenities within a 5-minute walking (400 meters). Whereas areas with more distant amenities report a lower score, with a zero-score given after a 30-minute address-amenities walking (when the amenities are more distant than one mile).

In the present study, the different school areas were categorized as "Walkable area" (50-100 scores) or "Car-dependent area" (0-49 scores) (www.walkscore.com).

\section{Statistical analysis}

General characteristics of the total group and for boys and girls as well as for urban and rural residents and for Northern, Central and Southern residents were described by means, standard deviations and frequencies.

ANOVA was performed to examine the effect of gender (boys vs girls), geographical area (North vs Centre vs South) and living setting (rural vs urban) on BMI, MQ and PA level, and to examine the effect of geographical area and living setting to Walk Score ${ }^{\circledR}$, followed by post-hoc analysis (Bonferroni adjustment) when significant main effects or interactions were observed. Effect size was also calculated using Cohen's definition of small, medium, and large effect size (as partial $\rrbracket^{2}=0.01$, $0.06,0.14)[22]$.

The chi-square test was used to compare variables' frequencies among groups (gender, geographical area and living setting). The chi-square test was also used to compare the frequencies of children attending schools located in walkable and cardependent areas between groups (gender, geographical area and living setting). 
A multinomial logistic regression analysis was used to assess whether MQ, PA level, geographical area, living setting, walkability (car-dependent vs walkable neighbourhood) and gender predicted BMI categories. Underweight and normal weight children were combined as "NW_UW category" which was set as reference group. Geographical area, living setting, walkability, and gender were added as factors, MQ and PA level were included in the analyses as covariates.

Statistical significance was set at $p \leq 0.05$ and all analyses were performed using IBM SPSS statistics version 25.

\section{Results}

\section{Characteristics of the population}

Characteristics of the subjects by gender, geographical area and living setting are shown in Table 1.

Table 1

Characteristics of the subjects by geographical area, living setting and gender $(n=1549)$.

\begin{tabular}{|c|c|c|c|c|c|c|c|c|c|c|c|c|}
\hline & \multicolumn{4}{|l|}{ North } & \multicolumn{4}{|l|}{ Centre } & \multicolumn{4}{|l|}{ South } \\
\hline & \multicolumn{2}{|l|}{ Rural } & \multicolumn{2}{|l|}{ Urban } & \multicolumn{2}{|l|}{ Rural } & \multicolumn{2}{|l|}{ Urban } & \multicolumn{2}{|l|}{ Rural } & \multicolumn{2}{|l|}{ Urban } \\
\hline & Boys & Girls & Boys & Girls & Boys & Girls & Boys & Girls & Boys & Girls & Boys & Girls \\
\hline & $(125)$ & (112) & $(270)$ & $(265)$ & $(130)$ & $(100)$ & (97) & (84) & (54) & (44) & $(143)$ & $(125)$ \\
\hline $\begin{array}{l}\text { Age } \\
\text { (years) }\end{array}$ & $\begin{array}{l}10.9 \\
\pm 1.4\end{array}$ & $\begin{array}{l}10.4 \\
\pm 1.4\end{array}$ & $\begin{array}{l}10.4 \\
\pm 1.6\end{array}$ & $\begin{array}{l}10.4 \\
\pm 1.7\end{array}$ & $\begin{array}{l}9.5 \pm \\
1.0\end{array}$ & $\begin{array}{l}9.4 \pm \\
0.9\end{array}$ & $\begin{array}{l}10.7 \\
\pm 1.3\end{array}$ & $\begin{array}{l}10.5 \\
\pm 1.2\end{array}$ & $\begin{array}{l}10.5 \\
\pm 1.3\end{array}$ & $\begin{array}{l}10.2 \\
\pm 1.0\end{array}$ & $\begin{array}{l}10.3 \\
\pm 1.4\end{array}$ & $\begin{array}{l}10.2 \\
\pm 1.4\end{array}$ \\
\hline $\begin{array}{l}\text { Weight } \\
\text { (kg) }\end{array}$ & $\begin{array}{l}40.2 \\
\pm 9.8\end{array}$ & $\begin{array}{l}39.3 \\
\pm 9.6\end{array}$ & $\begin{array}{l}37.9 \\
\pm 9.9\end{array}$ & $\begin{array}{l}36.8 \\
\pm 10.8\end{array}$ & $\begin{array}{l}37.9 \\
\pm 10.2\end{array}$ & $\begin{array}{l}37.3 \\
\pm 11.2\end{array}$ & $\begin{array}{l}40.9 \\
\pm 11.1\end{array}$ & $\begin{array}{l}39.2 \\
\pm 11.6\end{array}$ & $\begin{array}{l}40.2 \\
\pm 11.6\end{array}$ & $\begin{array}{l}35.6 \\
\pm 7.4\end{array}$ & $\begin{array}{l}39.5 \\
\pm 11.6\end{array}$ & $\begin{array}{l}38.5 \\
\pm 10.4\end{array}$ \\
\hline $\begin{array}{l}\text { Height } \\
\text { (cm) }\end{array}$ & $\begin{array}{l}145.1 \\
\pm 10.1\end{array}$ & $\begin{array}{l}141.3 \\
\pm 9.2\end{array}$ & $\begin{array}{l}143 \\
4 \pm \\
11.2\end{array}$ & $\begin{array}{l}141.6 \\
\pm 12.1\end{array}$ & $\begin{array}{l}138.4 \\
\pm 7.3\end{array}$ & $\begin{array}{l}137.1 \\
\pm 9.0\end{array}$ & $\begin{array}{l}144.1 \\
\pm 11.0\end{array}$ & $\begin{array}{l}142.5 \\
\pm 11.0\end{array}$ & $\begin{array}{l}146.5 \\
\pm 10.3\end{array}$ & $\begin{array}{l}143.8 \\
\pm 7.8\end{array}$ & $\begin{array}{l}144.4 \\
\pm 11.0\end{array}$ & $\begin{array}{l}143.0 \\
\pm 10.2\end{array}$ \\
\hline $\begin{array}{l}\mathrm{BMI} \\
\left(\mathrm{kg} / \mathrm{m}^{2}\right)\end{array}$ & $\begin{array}{l}19.0 \\
\pm 3.3\end{array}$ & $\begin{array}{l}19.5 \\
\pm 3.7\end{array}$ & $\begin{array}{l}18.2 \\
\pm 3.0\end{array}$ & $\begin{array}{l}18.0 \\
\pm 3.2\end{array}$ & $\begin{array}{l}19.6 \\
\pm 4.2\end{array}$ & $\begin{array}{l}19.5 \\
\pm 4.2\end{array}$ & $\begin{array}{l}19.4 \\
\pm 3.2\end{array}$ & $\begin{array}{l}19.0 \\
\pm 3.9\end{array}$ & $\begin{array}{l}18.5 \\
\pm 4.0\end{array}$ & $\begin{array}{l}17.2 \\
\pm 3.1\end{array}$ & $\begin{array}{l}18.6 \\
\pm 3.6\end{array}$ & $\begin{array}{l}18.6 \\
\pm 3.4\end{array}$ \\
\hline $\begin{array}{l}\text { MQ } \\
\text { (scores) }\end{array}$ & $\begin{array}{l}96.1 \\
\pm 16.0\end{array}$ & $\begin{array}{l}92.4 \\
\pm 13.6\end{array}$ & $\begin{array}{l}92.8 \\
\pm \\
15.6\end{array}$ & $\begin{array}{l}86.9 \\
\pm 15.5\end{array}$ & $\begin{array}{l}82.1 \\
\pm 11.8\end{array}$ & $\begin{array}{l}76.2 \\
\pm 12.5\end{array}$ & $\begin{array}{l}78.6 \\
\pm 13.8\end{array}$ & $\begin{array}{l}76.5 \\
\pm 13.1\end{array}$ & $\begin{array}{l}81.8 \\
\pm 13.9\end{array}$ & $\begin{array}{l}70.6 \\
\pm 11.8\end{array}$ & $\begin{array}{l}86.1 \\
\pm 17.0\end{array}$ & $\begin{array}{l}81.0 \\
\pm 14.8\end{array}$ \\
\hline $\begin{array}{l}\text { PA level } \\
\text { (scores) }\end{array}$ & $\begin{array}{l}2.7 \pm \\
0.6\end{array}$ & $\begin{array}{l}2.6 \pm \\
0.4\end{array}$ & $\begin{array}{l}2.6 \pm \\
0.5\end{array}$ & $\begin{array}{l}2.6 \pm \\
0.4\end{array}$ & $\begin{array}{l}2.4 \pm \\
0.7\end{array}$ & $\begin{array}{l}2.0 \pm \\
0.6\end{array}$ & $\begin{array}{l}2.5 \pm \\
0.9\end{array}$ & $\begin{array}{l}2.4 \pm \\
0.7\end{array}$ & $\begin{array}{l}2.6 \pm \\
0.6\end{array}$ & $\begin{array}{l}2.5 \pm \\
0.6\end{array}$ & $\begin{array}{l}2.4 \pm \\
0.6\end{array}$ & $\begin{array}{l}2.3 \pm \\
0.6\end{array}$ \\
\hline \multicolumn{13}{|c|}{ Data are expressed as mean \pm SD } \\
\hline
\end{tabular}

Globally, the results demonstrated that the prevalence of overweight and obesity was $22.0 \%(n=303$ children) and $9.9 \%$ ( $n=$ 136 children), respectively (sample $n=1377$ ). Within the overweight category, 171 children were boys $(56.4 \%)$ and 132 were girls (43.6\%); 122 were Northern (40.3\%), 98 were Central (32.3\%) and 83 were Southern (27.4\%) children; 115 were rural (38.0\%) and 188 were urban (62.0\%) children. Within the obesity category, 70 children were boys (51.5\%) and 66 girls (48.5\%); 43 were Northern (31.6\%), 65 were Central (47.8\%) and 28 were Southern (20.6\%) children; 76 were rural (55.9\%) and 60 were urban $(44.1 \%)$ children.

Regarding gross motor coordination, $47.9 \%$ of the total sample $(n=1549)$ showed MQ impairments $(n=742)$. Of these children, 352 were boys (47.4\%) and 390 were girls (52.6\%). Moreover, 259 were Northern (34.9\%), 274 were Central (36.9\%) and 209 were Southern (28.2\%) children; 272 were rural (36.7\%) and 470 were urban $(63.3 \%)$ children. 
Regarding PA level, $29.0 \%$ of the children $(n=793)$ were inactive $(n=230): 106$ were boys $(46.1 \%)$ and 124 were girls $(53.9 \%)$, 14 were Northern (6.1\%), 116 were Central (50.4\%) and 100 were Southern (43.5\%) children, 114 were rural (49.6\%) and 116 were urban $(50.4 \%)$ children.

\section{Effect of gender, geographical area and living setting on BMI}

The main effect of geographical area $\left(F_{1,1365}=9.62, p=0.000, \rrbracket^{2}=0.01\right)$ revealed that children from Central Italy had higher BMI than Northern and Southern children $\left(19.4 \pm 3.9 v s 18.5 \pm 3.3 v s 18.4 \pm 3.5 \mathrm{~kg} / \mathrm{m}^{2}\right.$, respectively).

Interestingly, geographical area $x$ living setting interaction $\left(F_{2,1365}=6.51, p=0.002, \rrbracket^{2}=0.01\right)$ showed that in the North of Italy rural children had higher BMI than urban children (Fig. 1).

Moreover, the chi-square test detected that the proportion of OW_OB children was different between the three geographical regions (North $27.1 \%$ vs Centre $39.9 \%$ vs South $30.8 \%, p=0.000$ ) and the two living settings (Rural $37.2 \%$ vs Urban $28.7 \%, p=$ 0.001).

\section{Effect of gender, geographical area and living setting on gross motor coordination (MQ)}

The main effect of gender $\left(F_{1,1537}=43.86, p=0.000, \mathbb{Q}^{2}=0.03\right)$ revealed that boys had higher MQ than girls $(88.0 \pm 16.2 \mathrm{vs}$ $83.1 \pm 15.6$ scores, respectively).

The main effect of geographical area $\left(\mathrm{F}_{2,1537}=133.14, p=0.000, \mathbb{\bigotimes}^{2}=0.148\right)$ showed that Northern children had the highest MQ, followed by Southern and Central children ( $91.3 \pm 15.7$ vs $81.8 \pm 15.9$ vs $78.7 \pm 12.9$ scores, respectively).

Geographical area $x$ living section interaction $\left(F_{2,1537}=15.88, p=0.000, \otimes^{2}=0.02\right)$ showed that in the North of Italy rural children had a higher MQ than urban children while in the South of Italy urban children had a higher MQ than rural children (Fig. 2).

The chi-square test revealed that the proportion of children with MQ impairments was different among the three geographical regions (North $33.5 \%$ vs Centre $66.7 \%$ vs South $57.1 \%, p=0.000$ ). In addition, there was a higher proportion of MQ impairments in girls than in boys $(53.4 \%$ vs $43.0 \%$, respectively, $p=0.000)$.

\section{Effect of gender, geographical area and living setting on PA level}

The main effect of gender $\left(F_{1,780}=6.03, p=0.014, \rrbracket^{2}=0.01\right)$ revealed that boys had a higher PA level than girls $(2.5 \pm 0.7 v s$ $2.3 \pm 0.6$ scores, respectively).

The main effect of geographical area $\left(F_{2,780}=7.39, p=0.001, \mathbb{Z}^{2}=0.02\right)$ showed that Northern children had the highest PA level, followed by Southern children and then Central children ( $2.6 \pm 0.4$ vs $2.4 \pm 0.6$ vs $2.3 \pm 0.8$ scores, respectively).

Geographical area $x$ living section interaction $\left(F_{2,780}=9.12, p=0.000, \nabla^{2}=0.02\right)$ showed that in the Centre of Italy urban children had a higher PA level than rural children while in the South of Italy rural children had a higher PA level than urban children (Fig. 3).

The chi-square test detected that the proportion of inactive children was different between the three geographical regions (North $9.6 \%$ vs Centre $38.0 \%$ vs South $29.3 \%, p=0.000$ ). Furthermore, there was a higher proportion of inactive children in girls than boys (34.1\% vs $24.8 \%$, respectively, $p=0.004)$.

\section{Effect of geographical area and living setting neighbourhood walkability}

The main effect of geographical area $\left(F_{2,1543}=170.76, p=0.000, \eta^{2}=0.18\right)$ revealed that children from the South of Italy attended schools located in neighbourhoods with the highest Walk Score ${ }^{\circledR}$, followed by children from the North and then by children from the Centre of Italy (75.7 \pm 16.6 vs $61.6 \pm 18.8$ vs $59.4 \pm 28.8$ score, respectively). 
The main effect of living setting $\left(F_{1,1543}=4304.10, p=0.000, \nabla^{2}=0.74\right)$ showed that urban children attended schools located in neighbourhoods with a higher Walk Score ${ }^{\circledR}$ than rural children (78.4 \pm 13.5 vs $39.9 \pm 11.1$ score, respectively).

Geographical area $x$ living setting interaction $\left(F_{1,1543}=167.68, p=0.000, \mathbb{Z}^{2}=0.18\right)$ revealed that in the North, the Centre and the South of Italy rural children attended schools located in neighbourhoods with a lower Walk Score $\circledast$ than urban children (Fig. 4).

The chi-square test revealed that the proportion of children attending schools located in car-dependent areas is different among the geographical regions (North $36.9 \%$ vs Centre $56.0 \%$ vs South $0 \%, p=0.000$ ). Moreover, there was a higher proportion of car-dependent areas in rural as compared to urban schools $(79.8 \%$ vs $6.5 \%$, respectively, $p=0.000)$.

\section{Determinants of BMI categories}

In order to model the relationship between BMI categories and several potential predictors (MQ, PA level, living setting, geographical area, walkability, and gender) a multinomial logistic regression was performed. $\mathrm{MQ}\left[\chi^{2}(2)=93.54, p=0.000\right], \mathrm{PA}$ level, $\left[\chi^{2}(2)=5.77, p=0.056\right]$, living setting $\left[\chi^{2}(2)=7.19, p=0.027\right]$, gender $\left[\chi^{2}(2)=10.58, p=0.005\right]$, and walkability $\left[\chi^{2}(2)=\right.$ $11.28, p=0.004]$ contributed significantly to the model.

Table 2 presents the results of the multinomial logistic regression. Lower MQ was associated with a higher risk for being affected by overweight and obesity. Lower PA level was associated with a higher risk for being obese and girls showed a lower risk for being obese. Interestingly, living in rural setting was associated with a higher risk for overweight and obesity and living in a car-dependent neighbourhood was associated with a higher risk for obesity. Finally, living in North, Centre or South of Italy did not predict the BMI categories. 
Multinomial logistic regression predicting BMI categories.

\begin{tabular}{|c|c|c|}
\hline & OW & OB \\
\hline & OR (95\% Cl) & OR (95\% Cl) \\
\hline \multicolumn{3}{|l|}{ Gender $^{a}$} \\
\hline Girls & $0.700(0.483-1.015)$ & $0.469(0.287-0.768)^{\star \star \star *}$ \\
\hline MQ (score) & $0.957(0.943-0.970)^{\star \star \star \star}$ & $0.927(0.910-0.945)^{\star \star \star \star}$ \\
\hline PA level (score) & $0.751(0.557-1.013)$ & $0.688(0.466-1.014) *$ \\
\hline \multicolumn{3}{|l|}{ Geographical area b } \\
\hline North area & $0.950(0.537-1.682)$ & $0.877(0.369-2.083)$ \\
\hline Centre area & $0.787(0.437-1.420)$ & $0.908(0.409-2.015)$ \\
\hline \multicolumn{3}{|l|}{ Living setting ${ }^{c}$} \\
\hline Rural setting & $0.540(0.287-1.016)^{*}$ & $0.333(0.117-0.949)^{\star \star}$ \\
\hline \multicolumn{3}{|l|}{ Walkability ${ }^{d}$} \\
\hline Car-dependent neighbourhood & $2.159(0.933-5.001)$ & 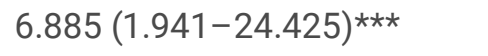 \\
\hline \multicolumn{3}{|c|}{$\begin{array}{l}\text { NW_UW was chosen as reference group for the outcome. }{ }^{\text {a }} \text { Reference category is "boys"; b Reference category is "South } \\
\text { area"; c Reference category is "urban setting"; d Reference category is "walkable neighbourhood". }\end{array}$} \\
\hline \multicolumn{3}{|c|}{${ }^{\star} p=0.05,{ }^{\star *} p<0.05,{ }^{\star * \star} p \leq 0.01,{ }^{\star * \star *} p<0.0001$} \\
\hline $\begin{array}{l}\text { Abbreviations: OW overweight, } \\
\text { MQ motor quotient. }\end{array}$ & N normal weight and und & dds ratio, $\mathrm{Cl}$ confidence interval, \\
\hline
\end{tabular}

\section{Discussion}

The first aim of the present study was to investigate whether differences between rural and urban settings in the North, Centre and South of Italy could influence school-age children's weight status, motor competence and PA level.

The hypothesis we formulated was confirmed because our findings showed that children from the Centre of Italy had the higher BMI than their peers from the North and the South, revealing the higher proportion of overweight and obese children in the Italian Central regions. These results were in contrast with previous studies' results that reported the higher prevalence of children's and adolescents' overweight and obesity in the South regions of Italy when compared with the Centre and the North regions $[4,5,16,23]$. Our Central children also showed the lowest PA level and the worst walkability of neighbourhoods when compared with their Northern and Southern peers that could have negatively affected their weight status. Moreover, the greater BMI of children living in rural areas of North Italy was consistent with results reported for children living in rural areas of Midwest in the United States [24] and for children living in rural areas of Croatia [12]. In addition, considering the different weight status categories, it appeared that rural children had a higher overweight/obesity prevalence than urban children, underling the severe situation of youth living in this setting. Although in the present study socioeconomic factors were not measured, rural children were often associated to a low family income [25]. Therefore, we could speculate that this low socioeconomic status of rural children leads to an unhealthy lifestyle which is directly related to low levels of PA, to a non-correct diet [26].and to a high prevalence of overweight and obesity [16]. 
Our results revealed a higher prevalence of motor impairments in girls than in boys, indicating that boys, at comparable ages, are more coordinated than girls. Similar results were previously observed in Portuguese children, suggesting that these differences could be due to different motor skills refinements, body growth and physical fitness levels between boys and girls [27]. This significant difference between boys' and girls' MQ could also be explained by referring to gender stereotypes in PA and sport practice $[28,29]$. Sport (i.e., football, athletics, basketball) has a strong masculine connotation, probably favouring males participation and practice in out-of-school settings and therefore their higher performance in motor tests $[28,29]$. Moreover, our results revealed that boys had a higher PA level than girls. The higher prevalence of physical inactivity among girls was consistent with results reported by other studies $[4,26]$. The low levels of gross motor coordination in combination with low levels of PA in girls suggests that this population needs to be targeted for priority intervention programs to promote PA and sport participation in girls. Northern children showed better gross motor coordination level when compared with Central and Southern children. These results could be explained by good leisure time facilities and the strong emphasis to promote exercise and sport practice in many Northern municipalities [4], thus providing an environment that could promote children's active behaviours. In fact, Northern children were the most active, showing the highest PA level than Southern and Central children. Contrarily, Central areas had more barriers to PA due to the lack of safety, green spaces, sports facilities and walkable neighbourhoods that could determine the worst MQ scores of children from the Centre of Italy (Fig. 2) [30]. Moreover, our Northern rural children had the higher MQ than their urban peers, showing an opposite scenario in the South of Italy, where urban children had the higher MQ than their rural peers. These controversial results were in line with results reported in previous studies conducted in different European Countries. Northern rural children scored better in the KTK test battery than their urban peers similarly to Spanish schoolchildren living in rural areas who obtained significantly better results in gross motor competence than children who lived in urban areas. ${ }^{7}$ Contrarily, Southern urban children showed higher KTK scores than rural children as also reported by Novak et al who showed that middle school Croatian students living in urban areas had better motor abilities than their rural counterparts [12]. It seems that there isn't a direct and univocal link between the area of residence (geographical area and living setting) and the level of motor coordination. Therefore, children's gross motor coordination level and its relationship with living setting is a topic that needs to be better investigated, particularly in Italian context.

The most active children were the Northern children. National data showed that the most of active children attends schools where at least 2 hours of weekly PA are performed and where there are initiatives promoting PA [31]. Moreover, school play time could contribute to children's daily PA levels [32]. In this perspective, school might play a fundamental role to affect PA level and sedentary behaviours in children. The school environment seems to be the ideal setting for the practice of PA, providing to a great number of children opportunities to be physically active during physical education classes and recess [29]. Nevertheless, only $34.5 \%$ of the classes from the primary schools of the Centre of Italy attends at least 2 hours of weekly PA, while more than $50 \%$ of the classes from the primary schools of the North and the South of Italy attends at least 2 hours of weekly PA (www.epicentro.iss.it/okkioallasalute) [4]. It seems that Italian schools have some barriers, such as the lack of appropriate areas, equipment, and organized activities during the school day, [33] to give children opportunities to accumulate PA during the school day. Our urban children of the Centre of Italy showed higher PA levels than their rural peers while children of the South of Italy showed higher PA levels than their urban peers (Fig. 3). These conflicting outcomes agreed with other controversial results of PA pattern in rural and urban children and adolescents in the United States [13].

The second aim of the present study was to analyse the walkability of the different school areas.

Neighbourhoods' characteristics were investigated by the Walk Score ${ }^{\circledR}$ which is a descriptor of the walkability of different areas. Our results showed that the higher proportion of schools in car-dependent neighbourhoods were in the Centre of Italy. These results were consistent with other Italian reports which showed the low level of walkability in urban areas of the Centre of Italy [30]. These results would emphasize the neighbourhood's criticalities that limit walkability and could be a basis to support public decisions to intervene in the development of the neighbourhoods aimed at encouraging PA. We defined urban or rural setting by population density. However, most rural schools of the present study were in car-dependent neighbourhoods where most errands require a car, limiting the use of active transportation as walking or biking. Therefore, 
considering the peculiarity of geographical and built environment characteristics of Italy, a new criterion to distinguish urban from rural areas could be introduced based on Walk Scoreß.

The present study showed the high incidence of overweight and obesity among Italian children, that could lead health problems as hypertension, cardiovascular, and metabolic diseases [23,34]. Therefore, to avoid immediate or future health complications, it is fundamental to understand which factors could be related to overweight and obesity in youth. Thus, the last aim of this study was to examine the relationship of Italian children's weight status with motor competence, PA level, geographical areas, living setting and neighbourhood walkability. The multinomial logistic regression results showed that lower MQ, lower PA level and living in a rural setting were associated with a higher risk for being overweight and/or obese. A Danish study reported similar results showing a significant relationship between body fatness and motor competence. [35]. A previous Italian investigation reported that lower PA level was associated with a higher risk for being obese [23]. The association between rural setting and children's obesity could be due to their lower socio-economic status [25] and therefore to the lower possibility to conduct a correct diet composed by healthy food [26] and to perform organized physical activities [36]. It was demonstrated that rural residency was associated with low levels of PA [37]. Children's PA levels that could influence children's weight status were often associated with structural influences, such as the physical environment (e.g. access to facilities, safety of neighbourhoods, weather conditions) [37]. Some environmental investigations showed that neighbourhood walkability and spatial structure of street networks affects PA and weight status condition in children [14, 15] In our study, living in neither walkable or car-dependent neighbourhoods predicted weight status. However, living in walkable areas is not strictly associated with positive walking behaviours [38]. This inconsistent relationship between walkability and BMI categories suggests conducting future studies to investigate the perceived availability of PA opportunities in youth. It might be possible that children perceived barriers to PA even in areas defined as walkable by an objective descriptor as the Walk Score ${ }^{\circledR}$. According to the theory of functioning and capabilities, the well-being is not only given by the simple availability of services and resources of an area, but also by the capability of the population to use them [39]. It might be possible that a neighbourhood or a region offers infrastructures or recreational areas where children can be active, but they are not able to use them as real resources.

Finally, although girls of our study had lower gross motor coordination and PA levels than boys, the logistic regression showed that being a girl was associated with a lower risk for being obese. These conflicting results could be explained by the fact that weight status categories were based on children's BMI. We could speculate that boys had a different body composition, characterized by higher lean body mass than girls, explaining their better gross motor coordination performances. It would be necessary to conduct body composition evaluations in future studies to verify it. However, our results were consistent with scientific literature that observed a higher prevalence of overweight and obesity among boys than girls although boys were more active than girls [40] who contrarily showed higher sedentary behaviours than boys [40]. Moreover, studies reported gender differences concerning behavioural determinants of overweight and obesity as different eating habits between boys and girls. Girls were more likely to eat healthy than boys, paying more attention to foods, calories intake and nutrients and preferring vegetables and fruits respect to boys [40].

Some limitations to this research should be noted. Central children were from Lazio region and Southern children were from Sicily region. Future studies should include children from more different regions. In addition, we compared the Metropolitan City of Rome with medium size cities. Future studies should include cities with similar size and population density. We investigated children's BMI, but we did not have indications regarding their body composition, eating habits, perceived availability of PA opportunities and socio-economic conditions that could influence the weight status. Finally, our data were based on an age-group (8 to 13 years old) that could make difficult to extend our conclusion to younger or older children and adolescents.

\section{Perspective}

The present work is an innovative contribution in understanding the links between children's health-related parameters and urban and rural setting in different Italian regions. Globally, Northern children showed better health-related parameters (lower 
BMI, higher MQ scores and PA levels) than Central and Southern children, suggesting that Northern children are able to benefit from the available services or interventions. Considering the alarming high percentage of children $(47.9 \%$ of the total sample) with motor coordination impairments, targeted PA interventions are mandatory. Moreover, the high percentage of overweight and obese children (31.9\%) suggests additional efforts to facilitate an active lifestyle and integrated healthy eating programs in Italian children.

\section{Declarations}

\section{Ethics approval and consent to participate}

The Institutional Review Boards of the University of Rome "Foro Italico", of the University of Verona and of the University of Palermo approved this investigation in accordance with the ethical standards laid down in the 1964 Declaration of Helsinki and its later amendments. Additional authorization was provided by school principals/administrators.

Written informed consent forms were obtained from both parents and children prior to study participation.

\section{Consent for publication}

Not applicable.

\section{Availability of data and materials}

The datasets used and/or analysed during the current study are available from the corresponding author on reasonable request.

\section{Competing interests}

The authors declare that they have no conflict of interest.

\section{Funding}

Not applicable.

\section{Authors' contributions}

MCG, ML, FS, VB, MG, MB, AP and GB design of the work, the acquisition, analysis, and interpretation of data; MCG, GZ and LF have drafted the work; SM, LG and CB substantively revised it. MCG was a major contributor in writing the manuscript.

All authors read and approved the final manuscript.

\section{Acknowledgments}

The authors are very grateful to the schools and to all children involved in the study, as without them this project could not be achieved.

\section{References}

1. Lima RA, Pfeiffer K, Larsen LR, Bugge A, Moller NC, Anderson LB, Stodden DF. Physical activity and motor competence present a positive reciprocal longitudinal relationship across childhood and early adolescence. J Phys Act Health 2017;14:440-447. doi: 10.1123/jpah.2016-0473.

2. DuBose KD, Gross McMillan A, Wood AP, Sisson SB. Joint Relationship between Physical activity, weight status, and motor skills in children aged 3to 10 years. Percept Mot Skills 2018;125:478-492. doi: 10.1177/0031512518767008. 
3. Moreira JPA, Lopes MC, Miranda-Júnior MV, Valentini NC, Lage GM, Albuquerque MR. Körperkoordinationstest für Kinder (KTK) for Brazilian children and ddolescents: Factor analysis, invariance and factor score. Front Psychol 2019;10:2524. doi: 10.3389/fpsyg.2019.02524.

4. Nardone P, Spinelli A, Buoncristiano M, Lauria L, Pierannunzio D, Galeone D. II Sistema di sorveglianza OKkio alla SALUTE: risultati 2016 [The Italian Surveillance system OKkio alla Salute: 2016 results]. Notiziario dell'Istituto Superiore di Sanità, Suppl. 1, Vol 31, n 7-8, Rome 2018. pp 29-36. ISSN 0394-9303.

5. Lauria L, Spinelli A, Buoncristiano M, Nardone P. Decline of childhood overweight and obesity in Italy from 2008 to 2016 : results from 5 rounds of the population-based surveillance system. BMC Public Health 2019;19:618. doi: 10.1186/s12889-019-6946-3.

6. Sallis JF, Glanz K. The role of built environments in physical activity, eating, and obesity in childhood. Future Child 2006;16:89-108. doi: 10.1353/foc.2006.0009.

7. Amador-Ruiz S, Gutierrez D, Martínez-Vizcaíno V, Gulías-González R, Pardo-Guijarro MJ, Sánchez-López M. Motor competence levels and prevalence of developmental coordination disorder in Spanish children: The MOVI-KIDS study. J Sch Health 2018;88:538-546. doi: 10.1111/josh.12639.

8. Tishukaj F, Shalaj I, Gjaka M, Ademi B, Ahmetxhekaj R, BachI N, Tschan H, Wessner B. Physical fitness and anthropometric characteristics among adolescents living in urban or rural areas of Kosovo. BMC Public Health 2017;17:711. doi: 10.1186/s12889-017-4727-4.

9. Carroll-Scott A, Gilstad-Hayden K, Rosenthal L, Peters SM, McCaslin C, Joyce R, Ickovics JR. Disentangling neighborhood contextual associations with child body mass index, diet, and physical activity: The role of built, socioeconomic, and social environments. Soc Sci Med 2013;95:106-114. doi: 10.1016/j.socscimed.2013.04.003.

10. Tainio M, Jovanovic Andersen Z, Nieuwenhuijsen MJ, Hu L, de Nazelle A, An R, Garcia LMT, Goenka S, Zapata-Diomedi B, Bull F, Sá TH. Air pollution, physical activity and health: A mapping review of the evidence. Environ Int 2021;147:105954. doi: 10.1016/j.envint.2020.105954.

11. Swinburn B, Egger G, Raza F. Dissecting obesogenic environments: The development and application of a framework for identifying and prioritizing environmental interventions for obesity. Prev Med 1999;29:563-570. doi: 10.1006/pmed.1999.0585.

12. Novak D, Bernstein ER, Podnar R, Vozzolo Y. Differences in the fitness levels of urban and rural middle school students in Croatia. Phys Educ 2015;72:553-576. doi: 10.18666/ TPE-2015-V72-I4-6115.

13. McCormack LA, Meendering J. Diet and physical activity in rural vs urban children and adolescents in the United States: A narrative review. J Acad Nutr Diet 2016;116:467-480. doi: 10.1016/j.jand.2015.10.024.

14. Galvez MP, Pearl M, Yen IH. Childhood obesity and the built environment. Curr Opin Pediatr 2010;22:202-207. doi: 10.1097/MOP.0b013e328336eb6f.

15. Ding D, Sallis JF, Kerr J, Lee S, Rosenberg DE. Neighborhood environment and physical activity among youth a review. Am J Prev Med 2011;41:442-455. doi: 10.1016/j.amepre.2011.06.036.

16. Bagordo F, De Donno A, Grassi T, Guido M, Devoti G, Ceretti E, Zani C, Feretti D, Villarini M, Moretti M, Salvatori T, Carducci A, Verani M, Casini B, Bonetta S, Carraro E, Schilirò T, Bonizzoni S, Bonetti A, Gelatti U; MAPEC_LIFE studygroup. Lifestyles and socio-cultural factors among children aged 6-8 years from five Italian towns: the MAPEC_LIFE study cohort. BMC Public Health 2017;17:233. doi: 10.1186/s12889-017-4142-x.

17. Cole TJ, Lobstein T. Extended international (IOTF) body mass index cut-offs for thinness, overweight and obesity. Pediatr Obes 2012;7:284-294. doi: 10.1111/j.2047-6310.2012.00064.x.

18. Kiphard EJ, Schilling F. Körperkoordinationstest für Kinder. Weinheim: Beltz Test GmbH; 2007.

19. Gobbi E, Elliot C, Varnier M, Carraro A. Psychometric properties of the physical activity questionnaire for older children in Italy: Testing the validity among a general and clinical pediatric population. PLoS One 2016;11:e0156354. doi: 10.1371/journal.pone.0156354. 
20. Chen SR, Lee YJ, Chiu HW, Jeng C. Impact of physical activity on heart rate variability in children with type 1 diabetes. Childs Nerv Syst 2008;24:741-747. doi: 10.1007/s00381-007-0499-y.

21. Duncan DT, Aldstadt J, Whalen J, Melly SJ, Gortmaker SL. Validation of Walk Score® for estimating neighborhood walkability: An analysis of four US metropolitan areas. Int J Environ Res Public Health 2011;8:4160-4179. doi: 10.3390/ijerph8114160.

22. Cohen J. Statistical Power Analysis for the Behavioral Sciences. New York, NY: Lawrence Erlbaum Associates; 1988.

23. Menghetti E, Strisciuglio P, Spagnolo A, Carletti M, Paciotti G, Muzzi G, Beltemacchi M, Concolino D, Strambi M, Rosano A. Hypertension and obesity in Italian school children: The role of diet, lifestyle and family history. Nutr Metab Cardiovasc Dis 2015;25:602-607. doi: 10.1016/j.numecd.2015.02.009.

24. Joens-Matre RR, Welk GJ, Calabro MA, Russell DW, Nicklay E, Hensley LD. Rural-urban differences in physical activity, physical fitness, and overweight prevalence of children. J Rural Health 2008;24:49-54. doi: 10.1111/j.17480361.2008.00136.x.

25. Andrade Neto F, Eto FN, Pereira TS, Carletti L, Molina Mdel C. Active and sedentary behaviours in children aged 7 to 10 years old: the urban and rural contexts, Brazil. BMC Public Health 2014;14:1174. doi: 10.1186/1471-2458-14-1174.

26. Bell L, Ullah S, Olds T, Magarey A, Leslie E, Jones M, Miller M, Cobiac L. Prevalence and socio-economic distribution of eating, physical activity and sedentary behavior among South Australian children in urban and rural communities: baseline findings from the OPAL evaluation. Public Health 2016;140:196-205. doi: 10.1016/j.puhe.2016.06.022.

27. Chaves R, Baxter-Jones A, Gomes T, Souza M, Pereira S, Maja M. Effects of individual and school-level characteristics on a child's gross motor coordination development. Int J Environ Res Public Health 2015;12:8883-8896. doi: 10.3390/ijerph120808883.

28. Gallotta MC, Marchetti R, Baldari C, Guidetti L, Pesce C. Linking coordinative and fitness training in physical education settings. Scand J Med Sci Sports 2009;19:412-418. doi: 10.1111/j.1600-0838.2008.00796.x.

29. Gallotta MC, Emerenziani GP, lazzoni S, lasevoli L, Guidetti L, Baldari C Effects of different physical education programmes on children's skill- and health-related outcomes: a pilot randomised controlled trial. J Sports Sci. 2017;35:1547-1555. doi: 10.1080/02640414.2016.1225969.

30. D’Alessandro D, Appolloni L, Capasso L. How walkable is the city? Application of the Walking Suitability Index of the Territory (T-WSI) to the city of Rieti (Lazio Region, Central Italy). Epidemiol Prev 2016;40:237-242. doi: 10.19191/EP16.34.P237.090.

31. Scarafile G. Childhood obesity in Italian primary schools: eating habits, physical activity and perception of weight by parents. Rev Health Care 2015;6:127-139. http://dx.doi.org/10.7175/rhc.v6i4.1211.

32. Ridgers ND, Stratton G, Fairclough SJ. Physical activity levels of children during school playtime. Sports Med 2006;36:359-371. doi: 10.2165/00007256-200636040-00005.

33. Hannus A, Lees M, Mägi K, Riimets A, Kalma M, Riso EM, Kull M. Perspectives of children and adolescents on the perceived determinants of physical activity during recess. Psychol Health Med 2018;23:1016-1024. doi: 10.1080/13548506.2017.1417611.

34. Di Bonito P, Pacifico L, Chiesa C, Valerio G, Miraglia Del Giudice E, Maffeis C, Morandi A, Invitti C, Licenziati MR, Loche S, Tornese G, Franco F, Manco M, Baroni MG; "CARdiometabolic risk factors in overweight and obese children in ITALY" (CARITALY) Study Group. Impaired fasting glucose and impaired glucose tolerance in children and adolescents with overweight/obesity. J Endocrinol Invest 2017;40:409-416. doi: 10.1007/s40618-016-0576-8.

35. Lima, RA, Bugge A, Ersbøll AK, Stodden DF, Andersen LB. The longitudinal relationship between motor competence and measures of fatness and fitness from childhood into adolescence. J Pediatr (Rio J) 2019;95:482-488. doi:

10.1016/j.jped.2018.02.010.

36. Finkelstein DM, Petersen DM, Schottenfeld LS. Promoting children's physical activity in low-income communities in Colorado: What are the barriers and opportunities? Prev Chronic Dis 2017;14:E134. doi: 10.5888/pcd14.170111. 
37. Swanson M, Schoenberg NE, Erwin H, Davis RE. Perspectives on physical activity and exercise among Appalachian youth. J Phys Act Health 2013;10:42-47. doi: 10.1123/jpah.10.1.42.

38. Ross SET, Clennin MN, Dowda M, Colabianchi N, Pate RR. Stepping it up: Walking behaviors in children transitioning from 5th to 7th grade. Int J Environ Res Public Health 2018;15:262. doi: 10.3390/ijerph15020262.

39. Sen A. Capability and well-being. In: Nussbaum M, Sen A (eds.). The Quality of Life. Oxford: Clarendon Press; 1993:3053. doi: 10.1093/0198287976.003.0003.

40. Greco E, Meo F, Cedrone F. Gender differences in childhood bmi z-score, alimentary behaviour and lifestyle in a sample of 9-11 children. Clin Ter 2020;171:e425-e430. doi: 10.7417/CT.2020.2240.

\section{Figures}

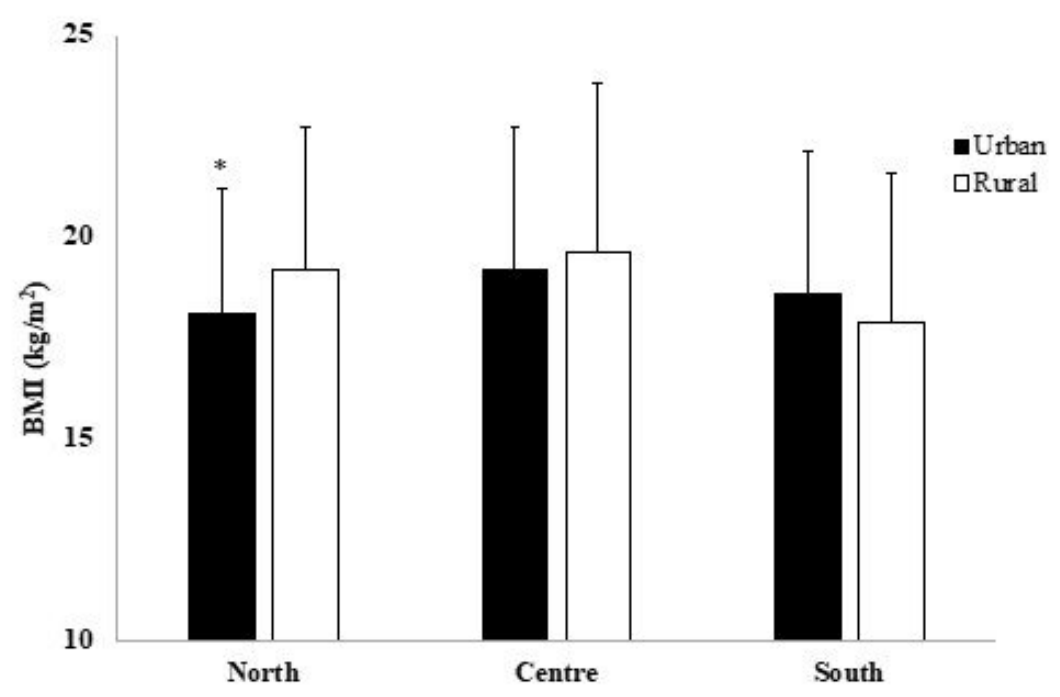

Figure 1

BMI in urban and rural children of the North, Centre and South of Italy. ${ }^{*} p=0.0001$ urban vs rural 


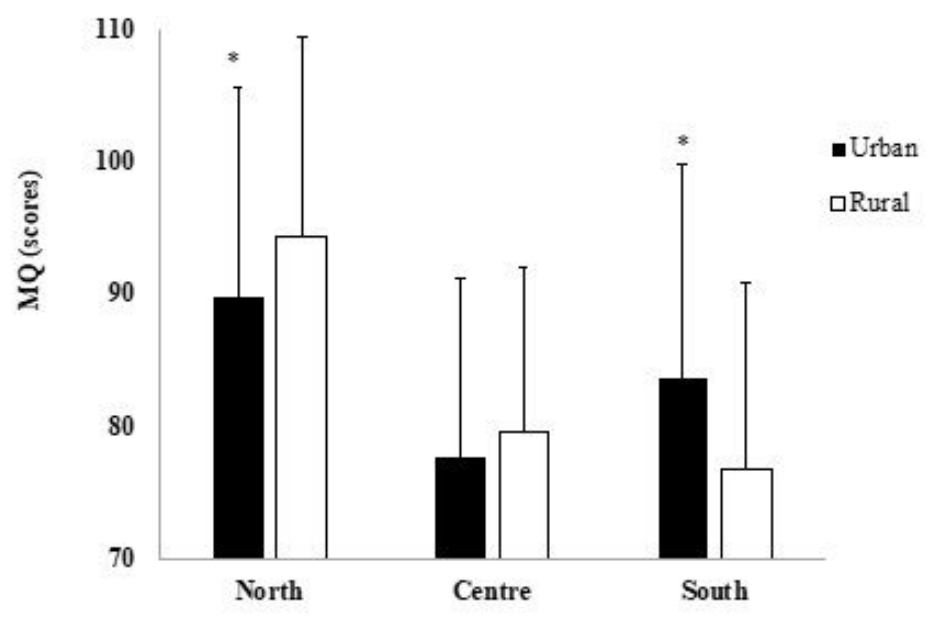

Figure 2

MQ in urban and rural children of the North, Centre and South of Italy. * $p=0.0002$ urban vs rural

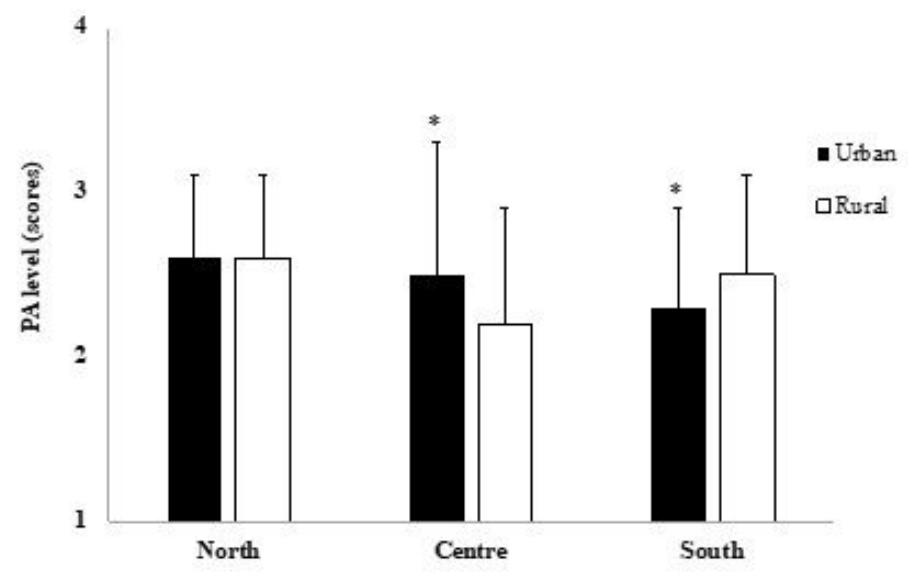

Figure 3

PA level in urban and rural children of the North, Centre and South of Italy. ${ }^{*} p \leq 0.01$ urban vs rural 


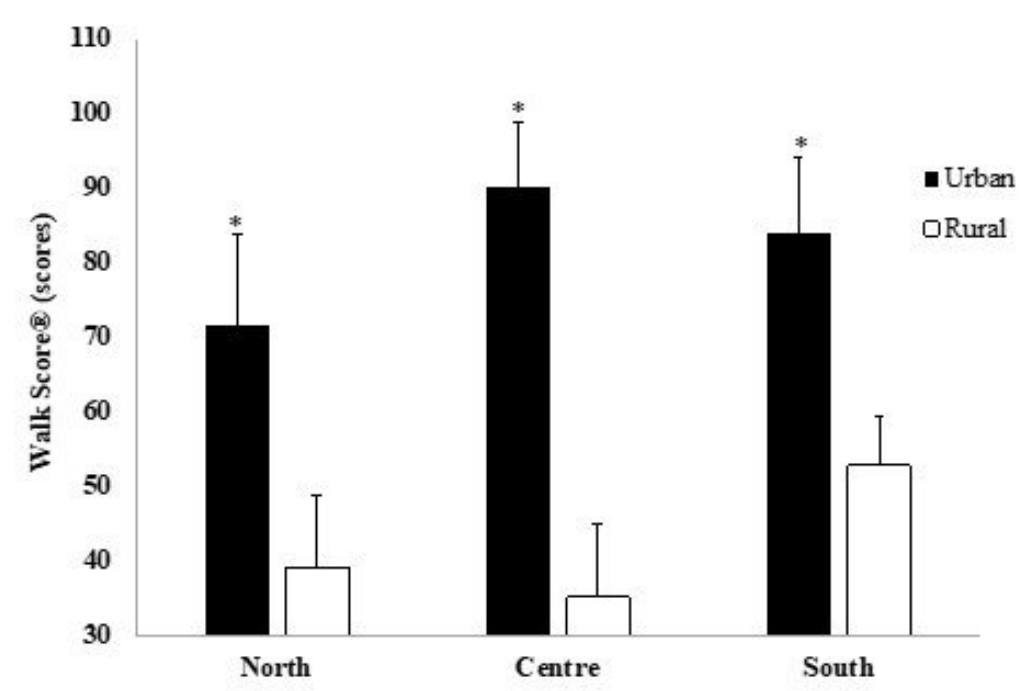

Figure 4

Walk Score ${ }^{\circledR}$ in urban and rural children of the North, Centre and South of Italy. * $p<0.0001$ urban vs rural 